\title{
An Investment Cost Analysis of Solar Hot Water System Combined with Economizer for Industry
}

\author{
Samnao Pansang and Sarayooth Vaivudh \\ School of Renewable Energy Technology, Naresuan University, Phitsanulok 65000, Thailand
}

Received: September 07, 2016 / Accepted: October 12, 2016 / Published: January 31, 2017.

\begin{abstract}
A combination of solar hot water system with the economizer for heating the water that circulates in the hot water storage tank is presented with the objective to reduce and analyze the cost of investment. The solar collector area will be affected to the investment cost of the solar hot water system. A combined system can be reduced the cost of solar collector by using the waste heat from the economizer to produce the hot water for reaching the requirement of the industry. In this paper the economizer installs in the boiler stack of the industry and produces hot water at $60{ }^{\circ} \mathrm{C}$ of 5,400 liter per day and the solar hot water system produces the hot water at the same temperature of 6,100 liter per day. The analysis is proposed by determining the solar collector plate area from the data and calculation. Investment cost of the system is 151,000 baht for the solar hot water system of 110,000 baht and the economizer of 410,000 baht for producing the total hot water of 115,000 liter per day.
\end{abstract}

Key words: Investment cost analysis, solar hot water system, economizer.

\section{Introduction}

Hot water is used in many industry processes for multipurpose as cleaning, disinfection, and transform material in some products. The conventional fuel for producing hot water is petroleum or fossil fuel as heavy oil, diesel, natural gas, or coal that release more waste heat, gas pollution and greenhouse gas that is not saving for human health and environmental. From the region of Thailand that experience of high solar radiation, there is more capacity of solar hot water production for using in the industrial activities [1]. Recently, the industry process uses more energy for producing the products and running many systems by investing the energy system that spend money for the fuel or electricity. Fossil fuel or electricity is selected to be the main energy that is simply using by conventional equipment and get more consumption for energy or fuel. The new environmental friendly equipment is presented to the industrial energy system for reducing

Corresponding author: Samnao Pansang, M.Sc., research field: solar hot water system. the fuel cost is solar energy, and waste heat energy that is available in every industry. Since of more and more area of solar collector can be installed in the industry, it will get more heat for using in the process. The hot water is very important of the industrial process in the production process and cleaning system, therefore the solar hot water system is selected for producing hot water for the industry without the energy cost due to free energy from the solar radiation. Hot water from the solar collector is transformed by the solar radiation that depends on the collector area and the loss in the system [2]. The hybrid source is a new technology to apply in present day to reduce the waste energy as shown in the case of solar hot water combined with the waste heat exchange from the economizer. An economizer is the heat exchanger of the waste heat gas to the water for preheating to the hot water system. These often take the form of loops, spiral or parallel arrays of finned tubing through which the feed water flows and over which the exhaust gases pass. They are available in modular form to be introduced into the exhaust stack or into the breeching [3]. 


\section{Solar Hot Water System Combined with the Economizer}

An active solar hot water system consists with the solar collector, the electric circulate pump, the hot water storage tank, and economizer for using waste heat that installs at the top of the exhaust stack of the boiler. The economizer is a heat exchanger of the boiler exhaust gas that transfers heat to the water for producing hot water to add the hot water in the system. The SHW (solar hot water) system combines to the economizer by the connection of the piping in closed loop system to the storage tank. Conventional solar collector for hot water is flat plate collector, a type of flat plate collector, which composes of cover glass, thermal insulator frame and bottom and the copper absorber tube for heating water that circulates in the tube as shown in Fig. 1 [4].

The hot water flow rate is produced by the solar radiation that converse to heat by the solar collector which install at the proper tilt angle and orientation of the collectors [5]. The flow rate of solar hot water system is calculated by the principle of energy balance of the radiation and the energy transform to heat the water in the collector by Eq. (1)

$$
q_{u}=A_{c}\left[G_{t}(\tau \alpha)-U_{L}\left(T_{p}-T_{a}\right)\right\rfloor=\dot{m} c_{p}\left(T_{o}-T_{i}\right)
$$

where,

$q_{u}$ is the energy rate of heat from the collector;

$A_{c}$ is the area of the solar collector;

$G_{t}$ is the solar radiation impact on the collector;

$\tau \alpha$ is the transmittance and absorptance respectively;

$U_{L}$ is the overall loss coefficient;

$T_{p}$ is the collector flat plate temperature;

$T_{a}$ is the ambient temperature;

$\dot{m}$ is the water flow rate in the solar collector;

$c_{p}$ is the water heat capacity;

$T_{o}, T_{i}$ are the inlet and outlet water temperature, respectively.

A solar flat plate is impacted by the radiation and produces the hot water depending on the area of the

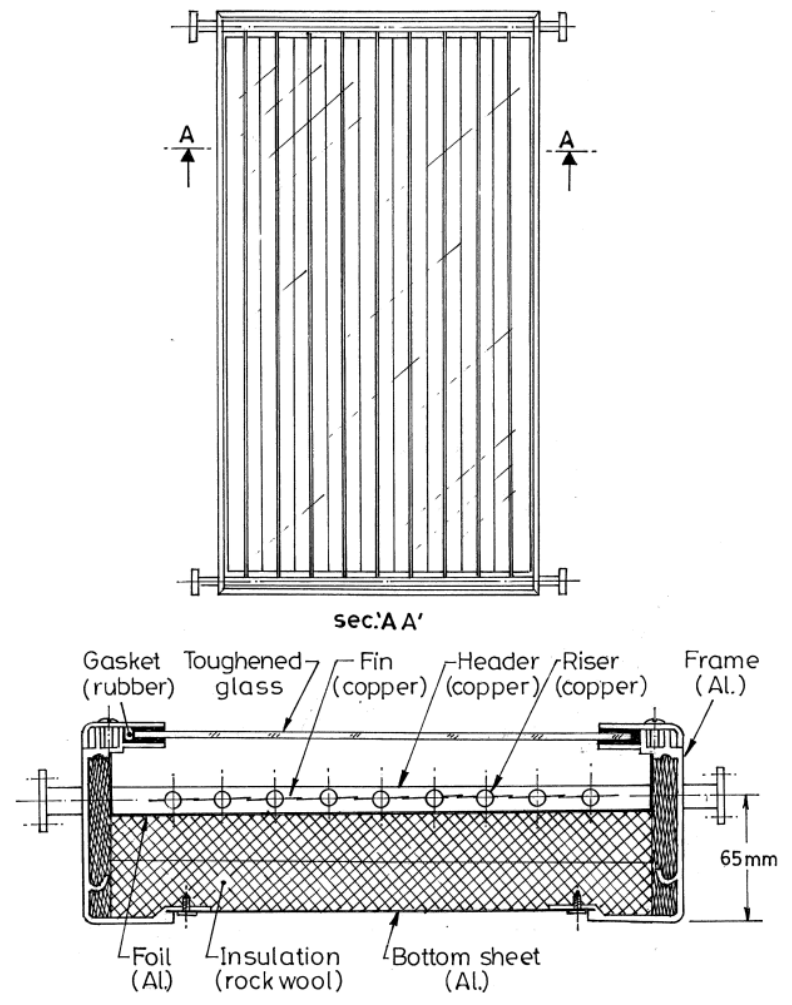

Fig. 1 A solar collector structure.

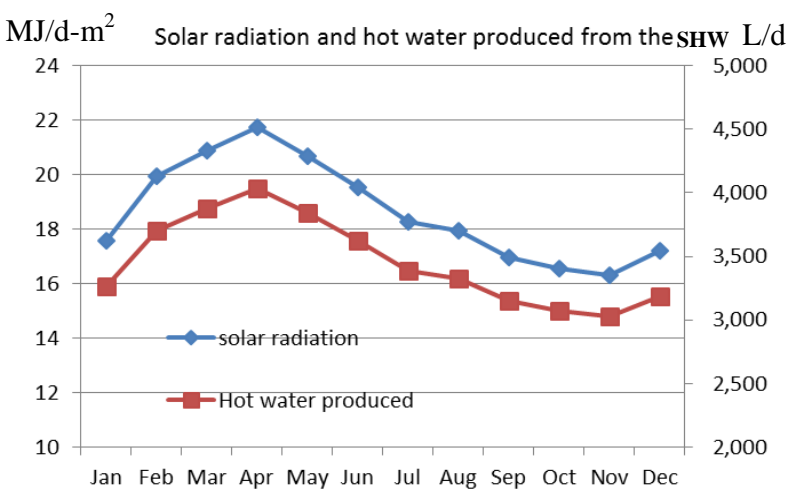

Fig. 2 The data of solar hot water system measuring and calculation.

collector and the radiation that varies by the time. The experiment result of the example solar collector flat plate area of $51 \mathrm{~m}^{2}$ is measured and compared to the calculation by Eq. (1) as shown in Fig. 2.

From Fig. 2 the variation of solar hot water is followed by the radiation that increased to maximum in April and minimum in November. The average of the hot water is 3,546 liter per day. An average hot water is varied by the area of the collector that could be calculated to find out by the data fit curve as done in the 
experimental and calculation. In the figure is shown the solar radiation in one year that is not constant in every month but the same average over the year with small error.

An economizer is a device that removes waste heat from the stack gas of some equipment in industry such as boiler, refrigeration or air condition. Waste heat is free and return to be the utilizing energy for reduction the investment cost for hot water system by the economizer. By recovering industrial waste heat, energy efficiency can be increased, greenhouse gas emissions can be reduced and the cost of waste heat disposal can be lowered [6]. Economizer composes with heat exchanger for transferring heat from the exhaust stack of the boiler to the water by the jacket tube as shown in Fig. 3 .

The hot water from the waste heat is recovered by the economizer with the capacity for preheating water or backup the system when the solar radiation is less by controlling the hot water temperature to set up at the same temperature of solar hot water [7].

\section{Hot Water for the Industry and the Investment}

Many industries use hot water for many activities to operate production in conventional from the electric heater or boiler but get the high cost in recent time. Presently the renewable energy is a better solution for producing the hot water for the industry by the solar and waste heat. A combination of renewable energy heat sources depends on the cost investment for optimum in cost and energy got from the design system. Hot water requirement of an example industry, Milott laboratories, Thailand with the amount of 11,500 liter per day is the research problem that needs to solve for the solar hot water system combined with the economizer. The input of the system is hot water requirement then the calculation is separated to optimum size of the solar hot water system and the investment cost for the waste heat. An economizer from the boiler is fixed by the size of the boiler

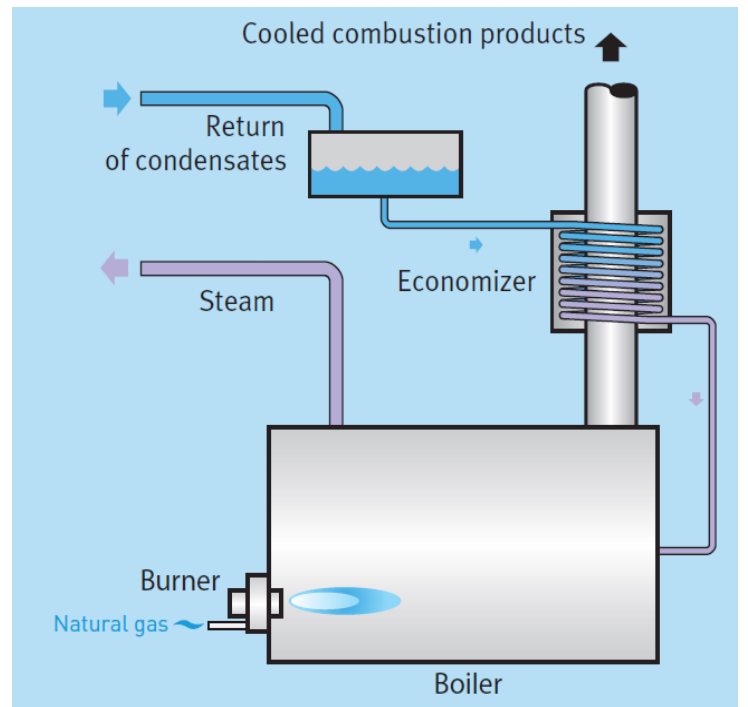

Fig. 3 The economizer diagram with the boiler stack of installation.

installed in the industry which calculates the hot water by heat exchanger equation for producing hot water of $60{ }^{\circ} \mathrm{C}$. In this paper, the capacity of the economizer from installing of the boiler is $18 \mathrm{~kW}$ that produces hot water of 5,400 liter in 12.5 hours which the system investment cost is 410,000 baht. There is more utilization for backup the system after sunset and the investment is suitable for the capacity of the boiler. The investment cost in the other capacity is increased by the size of the economizer capacity. The solar hot water system would produce hot water of 6,100 liter for sufficient of the industrial requirement and this amount is used to find the area of the solar collector. A schematic diagram of the combined system is shown in Fig. 4.

In Fig. 4, the economizer installs at the exhaust stack of the boiler in the industry for producing hot water parallel with the solar hot water system by the ratio of 1.13 respectively. The hot water system from the solar and economizer is used to collect the data and determine the investment cost analysis from the plate collector cost of the solar hot water system [8].

Since the solar hot water system combined with waste heat from the economizer not only reduces the cost of collector by including waste heat to the system but also decreasing the ambient temperature due to the 


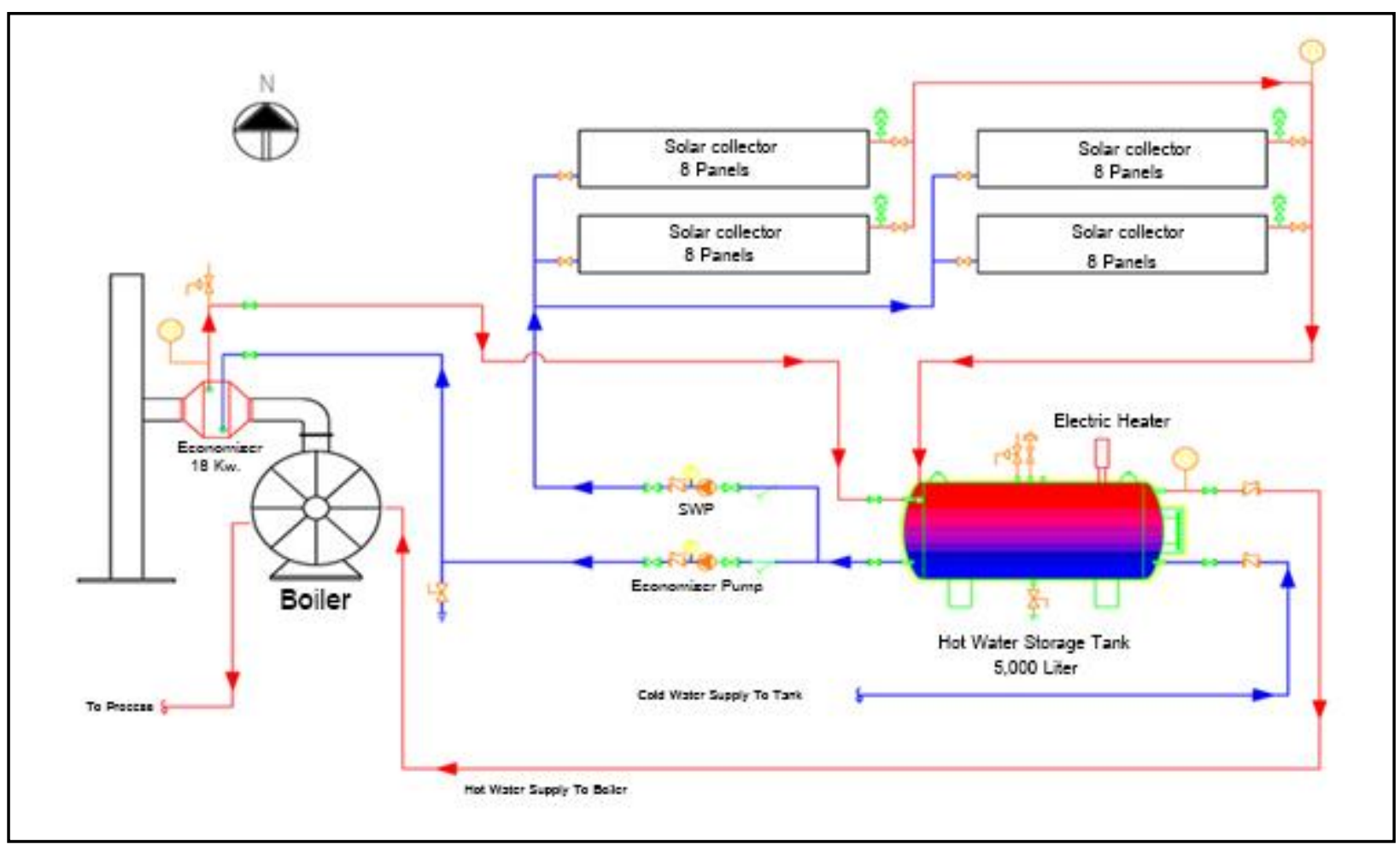

Fig. 4 Schematic diagram of the solar hot water combined with economizer system.

climate change and saving the boiler exhaust stack from heat.

\section{Experimental Setup}

The experiment for calculating the collector area is set up by the data from the real system that is installed in many areas of hotel, hospital, and some building that needs to use the hot water. Firstly, the experimental and the calculation of the hot water production by the solar collector area is collecting the data from the experiment as shown in Fig. 3 and secondly comparing to the calculation from the principle of energy balance for checking valid with the experiment. In average data of radiation in a year, therefore the hot water production can be calculated by Eq. (1). Fig. 5 is shown the satisfying of the experiment and calculation by the error less than $10 \%$.

This result is validated for the principle of energy balance by small error and there is utilized to estimate hot water in the other collector area for finding the collector size that concerns to the material cost.
Calculation result by fitting curve gives the equation for the case of annual solar radiation in Thailand as shown in Fig. 6.

In Fig. 5 the hot water from the collector is calculated for the criteria of temperature difference from $30{ }^{\circ} \mathrm{C}$ to $60{ }^{\circ} \mathrm{C}$ that is the suitable temperature of hot water using in the conventional industry. The requirement of the hot water is average of 6,100 liter per day that calculated by the equation from fitting curve is $86 \mathrm{~m}^{2}$, but it could be reduced to $60 \mathrm{~m}^{2}$ by increasing the collector efficiency from $50 \%$ to $70 \%$ since the collector decreases heat loss to the ambient with a good insulator. Cost of solar flat plate collector from surveying data is increased by the area and it can also determine with the same method of hot water as mention earlier. The cost equation from fitting curve of cost and area graph is shown in Fig. 6. This equation is based on the criteria of flat plate collector which the efficiency between $50-70 \%$ and the hot water is produced by the principle of energy balance of the solar radiation transfer of to heat. 


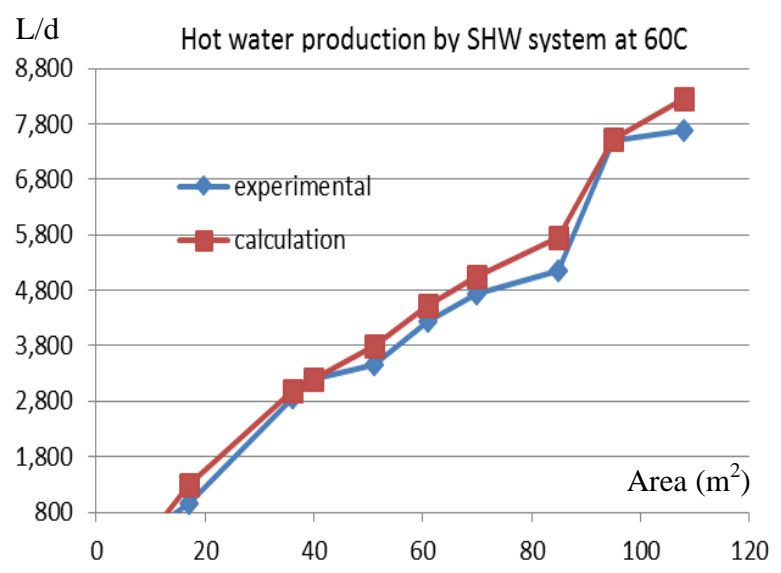

Fig. 5 The comparison of the experimental and calculation of the SHW.

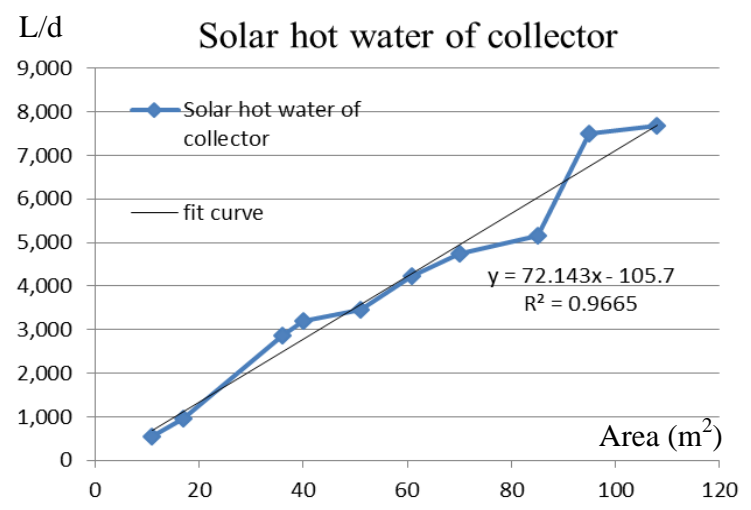

Fig. 6 Data fitting curve of the collector area and the hot water from the SHW.

Baht solar collector cost per area

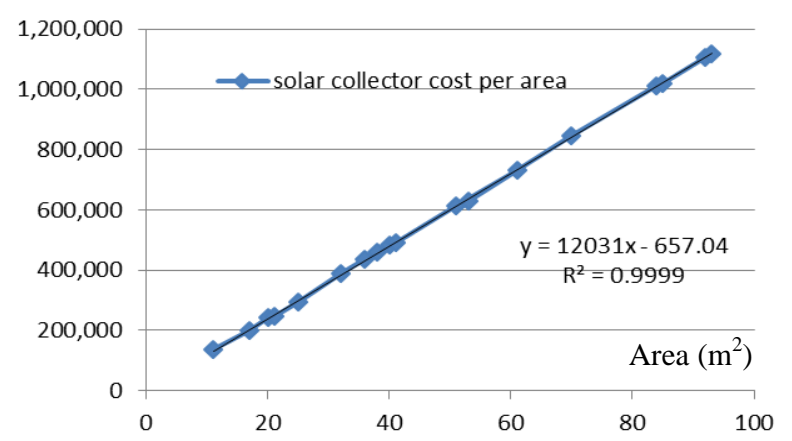

Fig. 7 The cost of solar flat plate collector versus the plate area.

\section{The Investment Analysis Method of Solar Hot Water and Economizer}

The cost of the solar collector is increased when the area also increases due to the cost of the cover glass and material included with the insulator. The collector cost from the survey data in many system of solar hot water is shown in the Fig. 7 and then the fitting curve is done by the linear equation for using to estimate the cost that gets from the first calculation input of $60 \mathrm{~m}^{2}$ and the output of 721,000 baht.

Total cost in the system includes with the storage tank of 5,000 liter and installation cost of solar hot water system. The economizer cost is composed with the equipment material of 380,000 baht and the installation cost of 30,000 baht. The investment cost of two hot water system, solar and economizer is shown in Fig. 8.

From Fig. 8 the major cost of investment is the solar hot water system which has the highest solar collector cost. The important is the reduction cost by increasing the efficiency of the collector for producing the hot water in the requirement of the system. When comparing this system to the system of LPG (liquefied petroleum gas) using, it founds that the LPG fuel consumption of $43.70 \mathrm{~kg}$ per day is calculated to the cost of 473,044 baht per year. Playback period of the system is 3.19 years and the cost of solar hot water is 0.16 baht per liter and the cost of the economizer hot water is 0.07 baht per liter. The cost of outlet hot water production by the two systems is 0.11 baht per liter from the investment of 151,000 baht that is minimum cost from the context and the analysis for hot water of the industry.

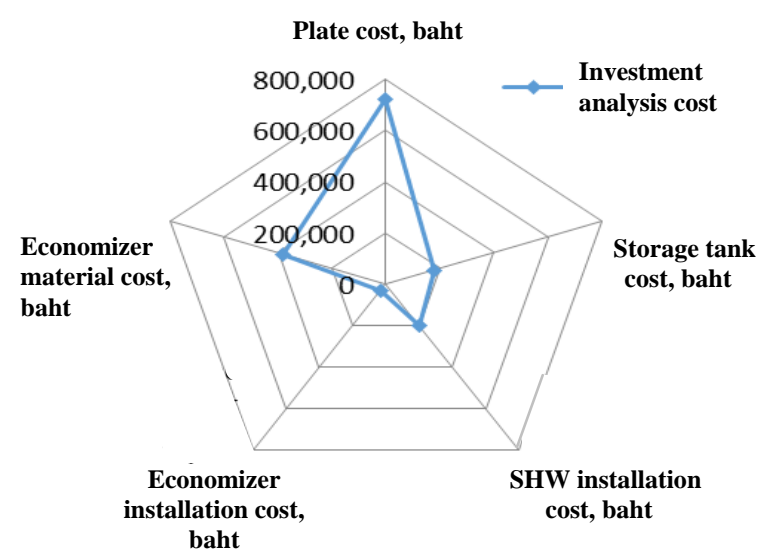

Fig. 8 The investment cost analysis of solar hot water with economizer. 
In Thailand, the renewable energy project as solar hot water is subsidized by DEDE (Department of Alternative Energy Development and Efficiency), Ministry of energy of Thailand, for saving energy project with the subsidy in this case of 4,500 baht per area. The investment cost is decreased by the subsidy to $1,240,000$ baht and the playback period result is reduced from 3.19 years to 2.62 years. This project is promoted for encouraging the investor to install by the lower cost and stimulate people to use renewable energy by the policy of energy saving.

\section{Conclusions}

The investment cost analysis of solar hot water system is composed with the data survey and the context in the industry about the waste heat and the method for transferring the waste heat to the water for combining to the system or even preheating in less radiation time. System production of the hot water which is calculated from the requirement based on the performance of the industry in this paper is 11,500 liter per day and capacity the economizer for producing hot water of 5,400 liter from the power of $18 \mathrm{~kW}$ and 6,100 liter from the solar collector. Estimation of the solar collector area is calculated by the fitting curve of the data and the result is $86 \mathrm{~m}^{2}$ for the collector efficiency of $50 \%$. The method of reduction the area for decreasing the cost by using high quality insulator and cover glass that decrease the heat loss and increase the efficiency of the collector to the area of $60 \mathrm{~m}^{2}$ and the cost is around 721,000 baht. Total cost for the whole system is 151,000 baht including the supporting equipment that is storage tank, installed worker payment and the piping system.

\section{References}

[1] Canivan, J. 2004. Solar Thermal Energy. USA: Sunny Future Press, 46.

[2] Degelman, L. O. 2005. "Calibrated Simulation of the Degradation of a Solar Hot Water System Performance over a 22 Year Period of Operation." Presented at the Ninth International IBPSA Conference, Montréal, Canada.

[3] Cardinale, N., Piccininni, F., and Stefanizzi, P. 2003. "Economic Optimization of Low Flow Solar Domestic Hot Water Plants.” Renewable Energy 28 (12): 1899-914.

[4] Nagaraju, J., Garud, S. S., Kumar, A., and Rao, M. 1999. "1 MWth Industrial Solar Hot Water System and Its Performance.” Solar Energy 66 (6): 491-7.

[5] Druck, H., Heidemann, W., and Steinhagen, H. M. 2004. "Comparison Test of Thermal Solar Systems for Domestic Hot Water Preparation and Space Heating." In Proceeding of Eurosun, 20-23 June: Freberg, Germany.

[6] Fang, H., Xia, J., Zhu, K., Su, Y., and Jiang, Y. 2013. "Industrial Waste Heat Utilization for Low Temperature District Heating." Energy Policy 62 (C): 236-46.

[7] Kalogirou, S. A. 2004. "Solar Thermal Collector and Applications." Progress in Energy and Combustion Science 30: 231-95.

[8] Charchalis, A., and Crefft, J. 2011. "Economizer Selection Method with Reference to Its Reliabiblity at Preliminary Design Stage of Seagoing Vessels." Journal of KONES Powertrain and Transport 18 (2): 63-8. 